\title{
CDS-Bond Basis Dynamic and Credit Spread Price Discovery: A Test for European Corporate and Sovereign Bond Markets
}

\author{
Michele Patanè $^{1}$, Mattia Tedesco $^{1}$, Stefano Zedda ${ }^{2}$ \\ ${ }^{1}$ Department of Business and Law, School of Economics and Management, University of Siena, Siena, Italy \\ ${ }^{2}$ Department of Business and Economics, University of Cagliari, Cagliari, Italy \\ Email:michele.patane@unisi.it,mat_ted@hotmail.it,szedda@unica.it
}

How to cite this paper: Patanè, M., Tedesco, M. and Zedda, S. (2019) CDS-Bond Basis Dynamic and Credit Spread Price Discovery: A Test for European Corporate and Sovereign Bond Markets. Modern Economy, 10, 1984-2003.

https://doi.org/10.4236/me.2019.108126

Received: July 10, 2019

Accepted: August 25, 2019

Published: August 28, 2019

Copyright () 2019 by author(s) and Scientific Research Publishing Inc. This work is licensed under the Creative Commons Attribution International License (CC BY 4.0).

http://creativecommons.org/licenses/by/4.0/

\begin{abstract}
This work analyzes the possible links between CDS premiums and bond spreads, with reference to both Eurozone sovereign and corporate markets, within the period 2011-2018. The main goal of this work is to provide more up-to-date results about the theoretical equivalence between the CDS premium and the credit spread of the underlying bond, and about the price discovery process of the credit risk between the CDS market and the bond market. While, theoretically, the CDS-bond basis must tend to zero, the analysis on all the considered markets has shown that it results to be constantly away from parity and, more specifically, positive on average. The analysis of the price discovery process of the credit risk between the CDS market and the bond market, analyzed by means of the VAR and VECM models, confirms the leader role of bond spreads for almost all the analyzed entities. These evidence could be useful for arbitrageurs, who want to take advantage of potential market inefficiencies, and for regulators interested in guaranteeing the financial system stability through timely and correct inclusion of all available information in the security prices, avoiding any adverse selection issue.
\end{abstract}

\section{Keywords}

CDS-Bond Basis, Credit Spread, Price Discovery, VAR, VECM

\section{Introduction}

The financial crises of the last decades have increasingly raised the attention to the correct evaluation of the financial instruments and the relevant risks.

First, the 2008 financial crisis and then the sovereign debt crisis underlined 
that one of the typical risk related to bond instruments-the credit rick-can play a key role in the price discovery process, and its importance for maintaining the bond market balance ${ }^{1}$. In the last few years, in fact, different regulations have been approved for enhancing the market transparency and the correct valuation of derivatives ${ }^{2}$.

The relationships between the credit risk, represented by CDSs, and the bond market have been widely discussed, in the aim of understanding whether the speculative use of these derivatives could negatively influence the dynamics of bond prices.

Essentially, the link between the CDSs and bonds is based on the Duffie theory (see [1]), who was the first to develop a CDS pricing model and to prove that the difference between the CDS premium and the bond spread must theoretically be equal to zero. The difference between the two values is called CDS-Bond Basis.

The Duffie theory is based on the fact that both CDS prices and bond prices are determined by the same elements: the credit risk value and the risk-free rate. Therefore, a portfolio made up of a bond and the purchase of a CDS on the same underlying bond, synthetically replicates the performance of a risk-free asset. This means that the difference (or spread, $S$ ) between the bond yield $(r)$ and the CDS premium $(P)$ must equalize the risk-free rate $(r f)$.

So:

$$
\begin{gathered}
P=r-r f \\
P=S
\end{gathered}
$$

Thus:

$$
S=r-r f
$$

Only if $P=S$ there is no possibility of arbitrage; if, on the other hand, the CDS-Bond Basis is different from zero, arbitrage strategies become possible, even if it typically has a very short duration, due to market efficiency.

Therefore, it is important to analyze how the link between CDS and bond ${ }^{1}$ For this reason, the ISDA (International Swaps \& Derivatives Association) was founded in 1985 in order to guarantee a safer and more efficient derivatives market. It introduced the so-called Big Bang Protocol in April 2009, a protocol with contractual standards signed by around 200 banks, professional investors and hedge funds. The aim of this protocol is to reduce systematic risk, promote the contract standardization and the central clearing.

${ }^{2}$ The reform of the financial regulation of the OTC derivatives market took place in the United States and Europe with two fundamental regulations, the Dodd-Frank Wall Street Reform and Consumer Protection Act and the European Markets and Infrastructure Regulation (EMIR) respectively. The first, introduced in the US in July 2010, brought changes about rules, controls and supervisory authorities in order to improve the transparency and accountability of the financial system. It has also made it mandatory to use a clearing house for OTC contracts. On the other hand, the second regulation was introduced in Europe in 2012 and made it mandatory several kinds of information, communication and behaviors and the use a clearing house for standardized OTC contracts. In Europe, it is worth mentioning also the MiFID I (2004) and MiFID II (2014) directives and the MiFIR regulation (2014). These regulations established that all derivative instruments, with a specific level of liquidity, are traded on regulated markets, MTFs (Multilateral Trading Facilities) or SI (Systematic Internaliser). 
spreads influences the price discovery process, so the mechanism through which it is possible to determine the price of a financial instrument, starting from the information available to each market participant. If a financial asset is traded in only one market, the price discovery process will take place in that market; if, on the other hand, the financial asset is traded in different markets, the price discovery process will possibly not occur in all markets at the same speed.

For this reason, it is important to identify which market is the first to incorporate the new information, thus leading the price discovery process.

The aim of this work is to analyze, through an econometric model, the relationship between the CDS market and the bond market, so to identify whether the new information tends to be absorbed firstly into CDS prices rather than bonds, or vice versa. Many studies analyzed this theme with reference to 2008-2012, but since then, there have been many changes in the financial markets: the size and liquidity of the markets have changed, the performance of government bond yields in most European countries has been reversed and important regulatory changes regarding the negotiation of CDS have been introduced in European and US regulations. We thus verified if more up-to-date results confirm the empirical hypotheses proved by [1], about the theoretical equivalence between the CDS premium and the credit spread of the underlying bond, and on the price discovery process of the credit risk between the CDS market and the bond market.

The analysis is carried out on both corporate and sovereign bonds, for the period 2011-2018. As regards to the sovereign market, the work analyzes six countries in the Eurozone area, three core countries (Germany, France and Belgium) and three peripheral countries (Italy, Spain, Portugal). The analysis on the corporate market is carried out on seven financial institutions and seven non-financial institutions, selected on the basis of the liquidity levels of their CDSs and bonds.

The reminder of the paper is organized as it follows: Section 2 is devoted to the related literature, Section 3 describes the dataset, Section 4 presents the preliminary analysis and the econometric approach, Section 5 reports the empirical results and Section 6 concludes.

\section{Literature Review}

The hypothesis underlying the correct functioning of financial markets is the so-called "no-arbitrage model". This means that financial assets prices reflect all the information available at a given time for these assets.

In dynamical terms, this means that as soon as new information is available, it is suddenly included in new expectations and prices. In this framework, it is important to understand whether the new expectations are firstly included into CDSs' prices and then in bonds', or vice versa, in the aim of verifying whether one of the two markets has a leading role in the price discovery process of credit risk. The study of these dynamics has been the subject of numerous studies over 
the last decade, both about the corporate market and the sovereign market.

As regards the corporate market, the most recent studies showed that the trend of the CDS-Bond Basis was close to parity in the years of relative financial calm, while it was persistently negative during the 2008 crisis. The analysis of price discovery process showed that the CDS market often had a leader role. In particular:

Reference [2] was the first to study the relationships between the credit spread and the CDS premium, using a sample of US and European investment grade companies in the 2002-2005 period. The authors identify a positive basis close to zero (around 6 bps). According to the authors, the positive basis is due to different reasons: 1) the presence of a "cheapest to delivery" option in the CDS with physical settlement, which allows the buyer to choose the most economic security among a basket of deliverable securities, causing a disadvantage for the contract seller; 2) the lower liquidity of the CDS market, therefore implicitly including a premium for this risk. As regards the price discovery process, the authors identify that the CDS market as a leader role for the bond market in $80 \%$ of their sample. The authors affirm that these results are due to the structural conditions of the CDS market, whose features make it easier to take short positions on credit risk in derivatives markets rather than bond markets.

Reference [3] analyzes the relationships between CDS premium and bond spread of European and US companies during the 1999-2002 period. The author identifies a basis close to zero in the years 1999-2001, while, starting from 2002, the CDS spread tends to be higher than the bond spread. The paper also shows that in the considered time span the price discovery process is driven by the CDS market, as it is more influenced by factors that define the credit quality of a reference entity.

Reference [4] was the first to study the dynamic of the CDS-Bond basis during the years of the recent financial crisis. The authors analyze a sample of US companies in the 2006-2009 period, identifying an extremely negative basis (from $-250 \mathrm{bps}$ to $-650 \mathrm{bps}$ ) especially for high yield companies, due, according to the authors, to the counterparty risk of derivative contracts. The authors also confirm the results of previous studies regarding the price discovery process.

Reference [5] analyzes a sample of US companies in the period 2006-2009. In particular the author carries out the analysis on three sub-periods: the pre-crisis period (January 2006-August 2007), in which the basis is almost equal to zero (3 bps); the period before the Lehman Brothers default (August 2007-August 2008), in which the basis is negative $(-36 \mathrm{bps})$; the period after the Lehman Brothers default (September 2008-August 2009), in which the basis reaches even -200 bps. According to this paper, the gradual decline of the basis is due both to the so-called "flight to liquidity", which pushes bond spreads higher, and to the increase in repo rates and haircuts.

As regards the sovereign market, the CDS market has had a strong growth only in the most recent period, due to the worsening of public debt and budget 
deficits suffered by almost all European countries after the 2008 financial crisis ${ }^{3}$. All studies agreed that the trend of the CDS-Bond basis was close to parity during the years 2004-2007, reaching around $40 \mathrm{bps}$ in the following period. In particular:

Reference [6] was the first to analyze the price discovery process between the CDS market and Government Bond one. The authors use a sample of 18 sovereign issuers divided into core countries, peripheral countries and developing countries. The analysis, carried out on period 2007-2010, confirm the presence of a long-run parity relationship between the prices of CDS and those of government bonds. According to the authors, the size of the CDS market for sovereign issuers is smaller than the outstanding securities. This can be a reason to explain a higher liquidity premium in derivative contracts. As regards the price discovery process, the authors achieve different results: for the core countries the bond market is a leader in the price discovery process, while for the peripheral and developed countries, the CDS market contributes more to the price discovery process.

Reference [7] carried out their analysis for the period 2006-2010, examining the following countries: Austria, Belgium, France, Germany, Ireland, Italy, the Netherlands, Portugal and France. The authors observe a positive basis for most countries, mainly due to the phenomenon of "flight to liquidity", since 2008. For PIIGS countries, the price discovery process is driven by the CDS market, while for the other countries the bond market has a leader role. On the other hand, there is no evidence about the price discovery process before 2008. This result is due to the recent development of the sovereign CDS market.

Reference [8] analyzes the relationship between CDS premium and bond spread for PIIGS countries in the period 2008-2011. The author observes the presence of a positive basis. One of the reasons is the different currency denomination for CDSs and Government bonds. In fact, CDS contracts are denominated in USD, instead, the bonds are denominated in EUR. This contributes, according to the author, to greater cost of the CDS. As regards the price discovery process, the author reaches the following results of previous works: for France and Italy, the leading market is that of government securities, while for Greece and Spain the CDS market has a leading role. For Portugal and Ireland, O'Kane D. observes a causality in both directions.

Reference [9] analyzed six European countries (Austria, Belgium, Greece, Italy, Ireland and Portugal) in the period 2001-2011. The authors find a basis close to zero in the period 2004-2007, while the basis is positive and more volatile in the period 2008-2009. As regards the price discovery process, they achieve the same result of previous works, thus the CDS market has a leading role.

In this work, the following studies have been taken as reference, the first for its

${ }^{3}$ This crisis mainly affected the so-called PIIGS countries (Portugal, Ireland, Italy; Greece, Spain) due to their higher public debt over the years, low GDP growth rates and higher burdens in financial institution rescue operations. These phenomena caused the fears of a possible default of the countries and the increasing need to cover the insolvency risk of government bonds. 
goals and the similar analysis methodology, while the second is one of the most recent study.

Reference [10] analyzed the relationships between CDS premium and bond spread for both sovereign and corporate markets. The sovereign market sample is made up of Germany, France, the United Kingdom and some peripheral European countries in the period June 2009-November 2010. The corporate market sample is made up of US and European companies in period September-December 2010. As regard the sovereign market, the authors observe a positive basis for all countries apart from Greece. According to [10] the negative basis is due to Greece downgrading/default expectations, the high repo rates and haircuts required for financing operations. As regards the corporate market, the authors observe a negative basis for issuers with a rating equal to or less than $\mathrm{BBB}$, a basis close to zero for issuers with A or AA rating; a positive basis ( $3 \mathrm{bps}$ ) for issuers with AAA rating. As regard the price discovery process, the authors confirm the leading role of the CDS market for countries like Spain, Greece and Ireland. For the other countries, instead, the results do not allow to define a leading market role.

Reference [11] analyzed the price discovery process of core and peripheral countries of the Eurozone in the period 2008-2014. The authors observe that there is a relationship between CDS premia and bond spread only during high volatility periods. During the two recent financial crises the CDS demand and the liquidity of the relative market increased, making the CDS market more efficient in the price discovery process. On the other hand, the bond market has a leader role when the credit risk has a negative trend.

In the same line of the papers cited above, which mainly analyzed this theme in the period 2011-2012, this study analyzed the possible links between CDS premiums and bond spreads, as regard both sovereign and corporate markets, in the period 2011-2018, for verifying if more up-to-date results confirm the previous findings about the price discovery process of credit risk between the CDS market and the bond market.

\section{Data}

The analysis is performed on two samples, of government bonds, and corporate bonds.

The government bond market analysis is performed with reference to six Eurozone countries, three of which belong to the core area (Germany, France and Belgium) and the other three belonging to the peripheral area (Italy, Spain and Portugal) (Table 1).

As regards the corporate market, due to their diversity in terms of size, concentration and risk levels, the analysis is performed with reference of a sample of listed companies based in the same countries selected for the sovereign market analysis, including a sub-sample of financial issuers (reported in Table 2), and a sub-sample of non-financial issuers. 
Table 1. Government bonds sample.

\begin{tabular}{cl}
\hline Country & Area \\
\hline Germany & Core \\
France & Core \\
Belgium & Core \\
Italy & Peripheral \\
Spain & Peripheral \\
Portugal & Peripheral \\
\hline
\end{tabular}

Table 2. Financial entities sample.

\begin{tabular}{ccc}
\hline Financial entity & Country & Business sector \\
\hline Commerzbank & Germany & Bank \\
Deutsche Bank & Germany & Bank \\
BNP Paribas & France & Bank \\
Société Générale & France & Bank \\
Intesa SanPaolo & Italy & Bank \\
Unicredit & Italy & Bank \\
Santander & Spain & Bank \\
\hline
\end{tabular}

As regards the "non-financial" sample, this study analyzes the companies, listed in Table 3, whose bond and CDS markets appear to be the most liquid.

The analysis is carried out using daily observations $s^{4}$ of CDS premiums and bond spreads during the period April 2011-September 2018.

As regards the CDS premiums, time series of both sovereign and financial/corporate entities, our analysis is performed on 5 years CDS, due to the higher liquidity of this market, which determines a higher reliability of the values. The considered values for CDS shave the following characteristics:

1) Financial/corporate CDS are denominated in EUR, while sovereign CDS are denominated in $\mathrm{USD}^{5}$.

2) Closing market mid price.

3) Single name ISDA ${ }^{6}$ contracts with physical delivery and notional equal to $€ 10,000,000$.

The different currency denomination of CDS premiums is due to the new ISDA standard, whose aim is to reduce the currency risk linked to CDS contracts. In the recent past, in fact, the risk of a possible default of a country has implicated an exchange rate swinging and so a depreciation of EUR currency. ${ }^{4}$ The analysis uses data coming from Bloomberg platform.

${ }^{5}$ As [8] showed, using contracts with different currency denominations between CDS and bonds could generate an exchange rate risk that leads CDS sellers to demand higher premiums, creating upward pressure on the CDS-Bond Basis.

${ }^{6}$ The single name (or plain vanilla) contracts are the simplest form of ISDA contracts, whose underlying is a single reference entity. 
Table 3. Non-Financial entities sample.

\begin{tabular}{ccc}
\hline Non-Financial entity & Country & Business sector \\
\hline Thyssenkrupp & Germany & Steel \\
Air Liquide & France & Chemical \\
Vivendi & France & Media and Communication \\
Telecom Italia & Italy & TLC \\
Eni & Italy & Energy \\
Orange & Spain & TLC \\
Telefònica & Spain & TLC \\
\hline
\end{tabular}

This means that the fair value of CDS premium would increase with a resulting impact on the buyer/seller of credit risk protection.

In order to calculate the CDS-Bond basis, the bond yields-issued by the same reference entity and with the same maturity date as the CDS contracts are needed. As regards the Government bonds, which have fixed maturities ${ }^{7}$, it is possible to use the market benchmark securities with a five years maturity. As regards the financial/corporate sample, instead, synthetic bonds with a maturity of 5 years have to be created. As already demonstrated in previous studies, these can be obtained by linearly interpolating the yields of two bonds, one with a shorter maturity and one with a longer maturity than that of the considered CDS. The method is so widely used that Bloomberg included in its platform a specific function ${ }^{8}$ for computing it.

Moreover, a risk free rate is needed for computing the bond spread. In the bond market, usually, the yield curve of government bonds of safe countries is used as benchmark. But in the recent years, government bonds seemed to be increasingly inadequate as the possibility of default of a country resulted to be actually real, so no government bond can be considered as risk-free rate. For overcoming this problem, [1] suggested the use of the General Collateral Rate (GCR), as to say the repo rate. However, the GCR is only available for maturities shorter than one year. Another chance used also for this study and in most of the previous studies, is to use as reference, the five-year swap rate curve. These are, in fact, synthetic derivatives quoted on constant maturities with unlimited amount.

\subsection{CDS-Bond Basis Dynamics}

As shown in Figure 1, the CDS premium and bond spread, as regards the financial sample, have a common negative trend. On the other hand, the CDS-Bond Basis is positive (21 - 75 bps on average) for the entire financial sample, with ${ }^{7}$ Equal to 3, 5, 10, 15, 30, 50 years.

${ }^{8}$ Bloomberg uses the securities' mid price after the market closing and it is referred to senior bonds, with no guarantee, fixed coupons and without options or step-up clauses. 

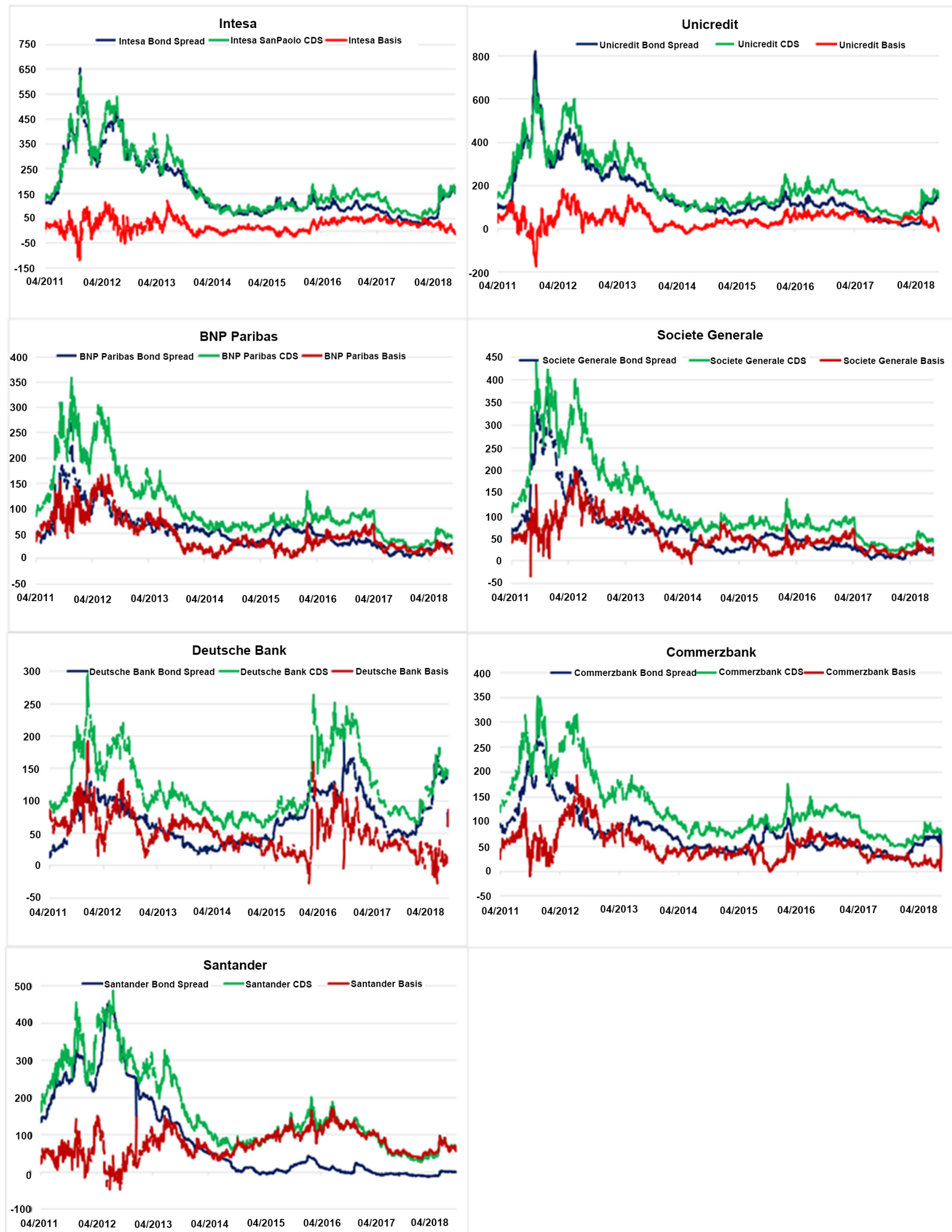

Figure 1. CDS-Bond Basis dynamics for Financial sample. 
some negative peaks during the first years of the considered time span, which refer to the years just after the financial crisis, characterized by strong instability and economic weakness. The long-run trend of the three variables is common to all the observed entities, except for Deutsche Bank, for which there is a strong increase in the three variables between the second half of 2016 and the first half of 2017, due to the news related to its involvement in some market violations starting from the 2000s, and to the subsequent penalties inflicted by the US and UK.

As shown in Figure 2, the CDS premium and bond spread, as regards to the non-financial sample, have a common negative trend. On the other hand, the CDS-Bond Basis is positive (16 - 34 bps on average) for the entire financial sample, with just some specific and differentiated negative peaks, which can be attributed to the differences among the sectors of the examined companies.

As regards the sovereign sample, reported in Figure 3, the CDS premium and bond spread have a common negative trend, except for those of Germany, which influence is so big that the CDS-Bond Basis for the whole sovereign sample results to be is positive (17 - 80 bps on average). The Basis has positive peaks for core countries and negative peaks for peripheral countries, due to the "fight to liquidity" ${ }^{\prime \prime}$ phenomena and the higher liquidity ${ }^{10}$ of sovereign bonds considered as safer assets.

Starting from the second half of 2014, the basis is positive for the entire sovereign sample, due to the ECB monetary policy, which led to lower interest rates, which reached zero in November 2014, and to the Quantitative Easing started in 2015. We thus split the considered time span, and performed the analysis separately for the two different time periods, from April 2011 to April 2014, and from May 2014 to September 2018.

Table 4 reports the descriptive statistics for each time series of the dataset, which show respectively the number of observations, the mean and the standard deviation.

\subsection{Preliminary Analysis and Econometric Approach}

A null CDS-Bond basis in the long-run means that there is a common trend between the time series of CDS premiums and bond spreads. Therefore, testing the presence of cointegration ${ }^{11}$ between the two time series is important to prove the existence of a null basis in the long-run. Two or more time series are cointegrated if they have a common stochastic trend, which means that there is a static equilibrium between the time.

${ }^{9}$ This phenomenon occurs when investors sell an asset that is considered less liquid and riskier, to the benefit of assets considered safer, such as government bonds of core countries or bonds of investment grade issuers.

${ }^{10}$ The CDS value and the related bond include a liquidity premium. As the CDS market is more or less liquid than the bond one, this implies a liquidity premium in the CDS prices, respectively lower or higher than bond credit spread, influencing the value of the basis.

${ }^{11}$ The cointegration occurs only when two or more time series are not stationary. This means that there is cointegration between the two non-stationary processes of order $(d)$, if there is a combination of these which is a stationary process $I(0)$ 

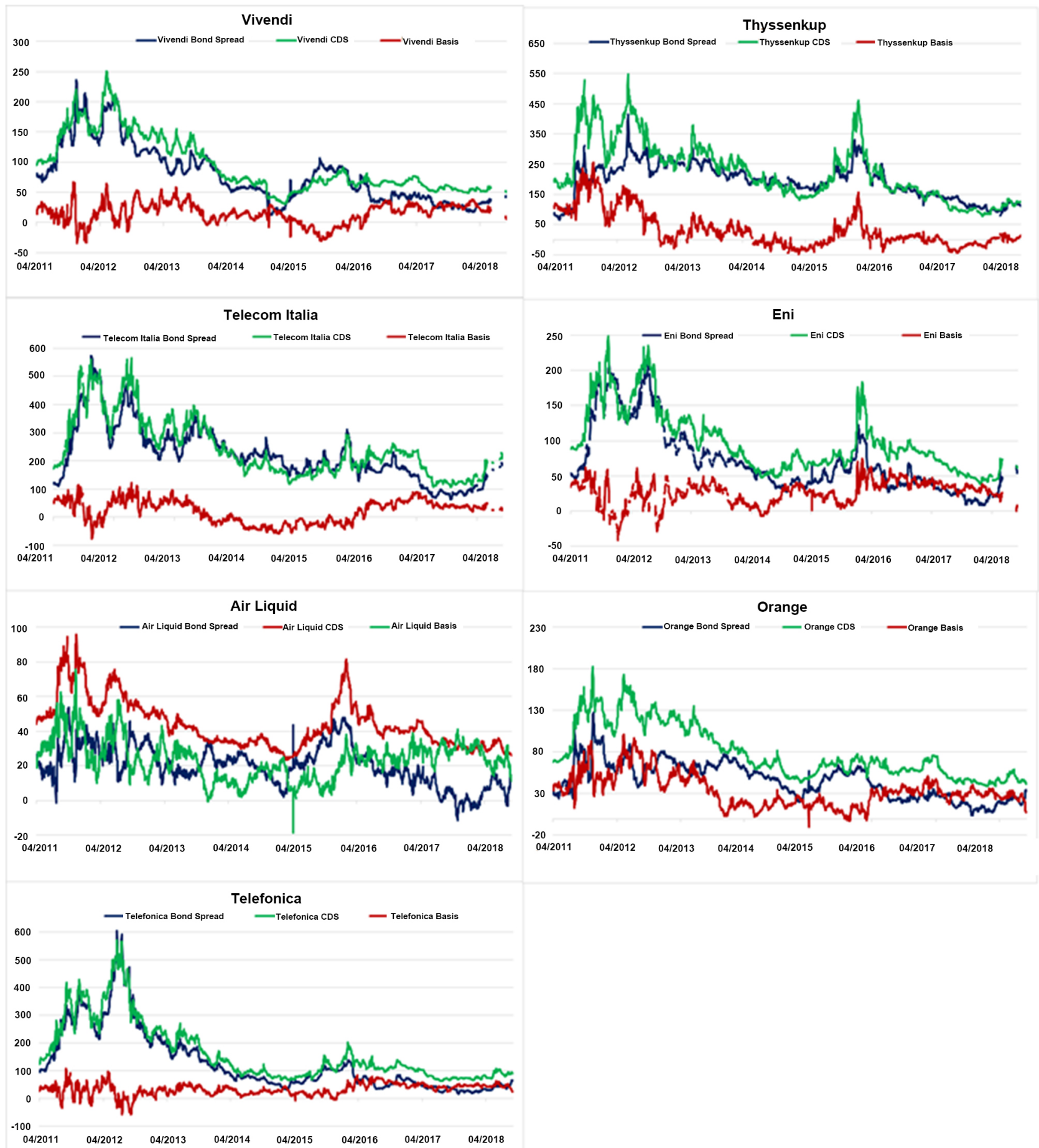

Figure 2. CDS-Bond Basis dynamics for Non-Financial sample.

In this work we use both the Johansen ${ }^{12}$ and the Engle and Granger ${ }^{13}$ tests to prove the presence of cointegration between the two time series, in order to ${ }^{12}$ The Johansen test is used to test if two or more time series are cointegrated. The test examines the rank of the cointegration matrix as described by [12]. Formally, given a $I(1)$ model and a generic $\mathrm{k}$-so $\Delta y_{t}=-\pi y_{t}-1+\varepsilon_{t}$, where $\pi$ is the cointegration matrix with maximum rank $\mathrm{k}-$ the test examine the rank of the matrix $\pi$ through the following steps: 


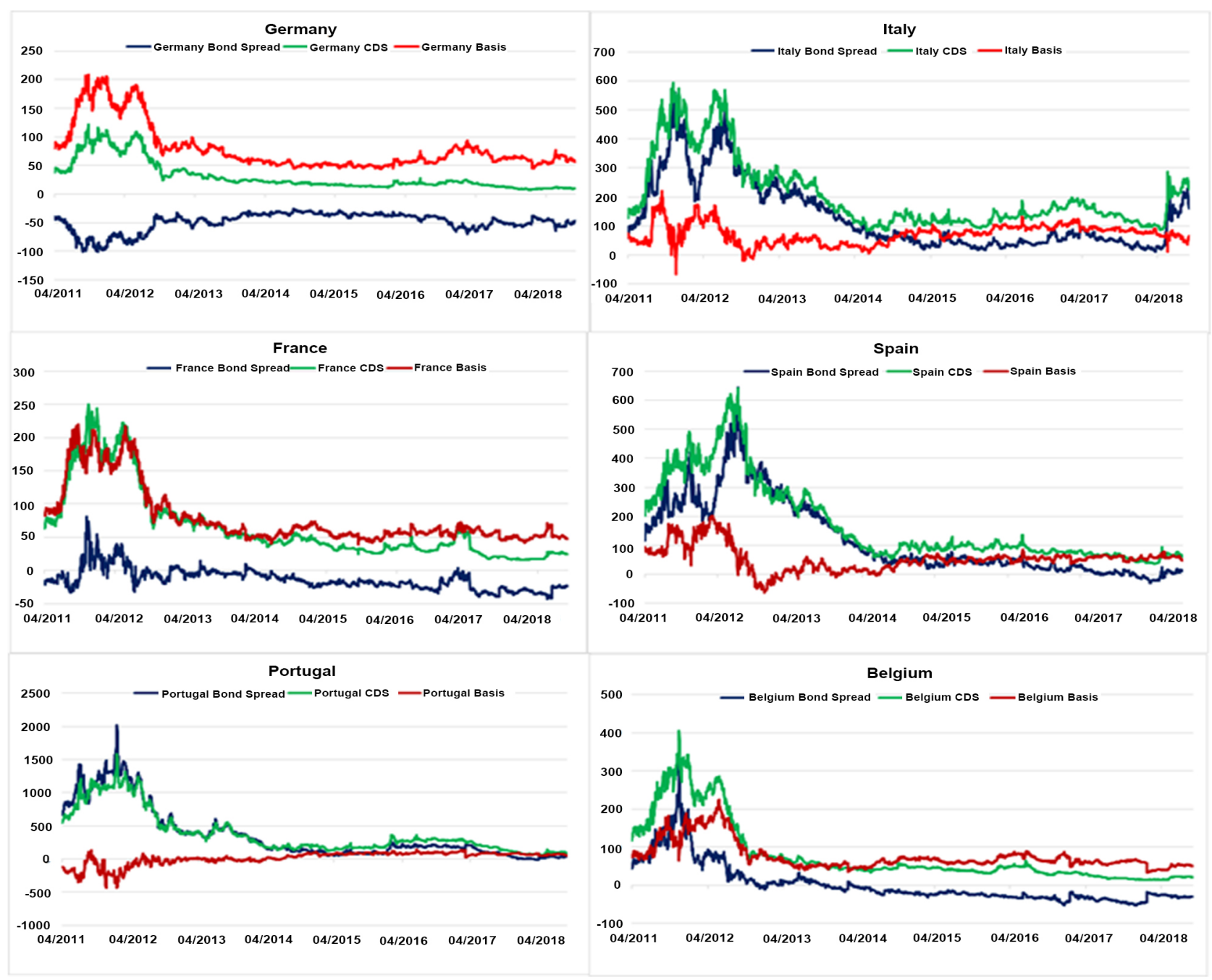

Figure 3. CDS-Bond basis dynamics for sovereign sample.

1) H0 (Rank = 0) vs H1 (Rank > 0). If null hypothesis is not rejected, then there is no cointegration between vectors. On the other hand, if the null hypothesis is rejected, then there is at least a cointegration vector.

2) Then, H0 (Rank = 1) vs H1 (Rank > 1). If the null hypothesis is rejected, then there is a cointegration vector. On the other hand, if the null hypothesis is rejected, there are at least two cointegration vectors.

3) This process works with test on higher rank until the null hypothesis is not rejected. If the null hypothesis is rejected when testing the maximum rank, the time series are not cointegrated and not stationary.

Below all possible results after the test:

1) Rank $=0$ : all time-series are not stationary and not cointegrated;

2) Rank $=1$ : all time-series are not stationary and cointegrated;

3) Rank $=2$ : all time-series are stationary and not cointegrated.

${ }^{13}$ The Johansen test leads often to wrong results, such as rejecting the null hypothesis of no cointegration. This happens because a common trend between economic variables is caused by complex interactions between different elements, which are difficult to identify. For this reason, the equilibrium of the long-run relationship between CDS premium and bond spread is also verified by means of the Engle-Granger test. This test analyzes the regression $y_{t}=\beta_{0}+\beta_{1} x_{t}+$, where $y_{t}$ and $x_{t}$ are the two different processes (CDS and bond spreads), then it stores the residuals $\varepsilon t$ and carries out the unit root test (Dickey-Fuller test) on the residuals in order to verify if they are stationary. If the residuals are stationary, then a linear stationary combination of $y_{t}$ and $x_{t}$ exists, so the two processes are cointegrated (see [13]). 
Table 4. Descriptive statistics.

\begin{tabular}{|c|c|c|c|c|c|}
\hline Sample & Entity & Variable & Obs & Mean & Std. Dev. \\
\hline \multirow{14}{*}{$\begin{array}{l}\text { Financial corporate } \\
\text { sample }\end{array}$} & \multirow{2}{*}{ IntesaSanPaolo } & Bond & 1936 & 223.8288 & 159.949 \\
\hline & & CDS & 1936 & 176.5421 & 114.4459 \\
\hline & \multirow{2}{*}{ UniCredit } & Bond & 1936 & 243.3868 & 176.2055 \\
\hline & & CDS & 1936 & 212.6215 & 131.545 \\
\hline & \multirow{2}{*}{ BNP Paribas } & Bond & 1936 & 123.4868 & 92.22734 \\
\hline & & CDS & 1936 & 99.44283 & 63.22024 \\
\hline & \multirow{2}{*}{ SociétéGénérale } & Bond & 1936 & 135.4512 & 115.9673 \\
\hline & & CDS & 1936 & 119.2966 & 84.58553 \\
\hline & \multirow{2}{*}{ DeutscheBank } & Bond & 1936 & 146.7232 & 59.14231 \\
\hline & & CDS & 1936 & 123.9791 & 43.72524 \\
\hline & \multirow{2}{*}{ CommerzBank } & Bond & 1936 & 144.508 & 97.54702 \\
\hline & & CDS & 1936 & 126.3052 & 59.14076 \\
\hline & \multirow{2}{*}{ Santander } & Bond & 1936 & 166.2512 & 175.3955 \\
\hline & & CDS & 1936 & 156.5169 & 100.1498 \\
\hline \multirow{14}{*}{$\begin{array}{l}\text { Non-Financial } \\
\text { corporate sample }\end{array}$} & \multirow{2}{*}{ Vivendi } & Bond & 1936 & 156.4874 & 105.2335 \\
\hline & & CDS & 1936 & 957.277 & 46.18623 \\
\hline & \multirow{2}{*}{ Thyssenkrupp } & Bond & 1936 & 267.4002 & 94.50681 \\
\hline & & CDS & 1936 & 225.9291 & 95.7954 \\
\hline & \multirow{2}{*}{ Telecom Italia } & Bond & 1936 & 300.4848 & 148.152 \\
\hline & & CDS & 1936 & 245.5792 & 103.8226 \\
\hline & \multirow{2}{*}{ Eni } & Bond & 1936 & 148.7673 & 103.0528 \\
\hline & & CDS & 1936 & 98.75479 & 43.16216 \\
\hline & \multirow{2}{*}{ Air Liquid } & Bond & 1936 & 95.26478 & 73.87698 \\
\hline & & CDS & 1936 & 44.05934 & 13.84592 \\
\hline & \multirow{2}{*}{ Orange } & Bond & 1936 & 120.8782 & 83.4405 \\
\hline & & CDS & 1936 & 79.80429 & 31.98928 \\
\hline & \multirow{2}{*}{ Telefonica } & Bond & 1936 & 206.2219 & 164.0505 \\
\hline & & CDS & 1936 & 164.8542 & 106.4995 \\
\hline \multirow{12}{*}{$\begin{array}{c}\text { Sovereign sample } \\
\text { (Apr. 2011-Apr. 2014) }\end{array}$} & \multirow{2}{*}{ Germany } & Bond & 798 & 85.02995 & 55.12994 \\
\hline & & CDS & 798 & 52.69386 & 28.52075 \\
\hline & \multirow{2}{*}{ Italy } & Bond & 798 & 388.4534 & 120.6 .666 \\
\hline & & CDS & 798 & 309.2732 & 128.002 \\
\hline & \multirow{2}{*}{ France } & Bond & 798 & 141.9738 & 60.89029 \\
\hline & & CDS & 798 & 113.085 & 57.78981 \\
\hline & \multirow{2}{*}{ Spain } & Bond & 798 & 397.1912 & 110.1692 \\
\hline & & CDS & 798 & 3.2 .1766 & 126.9553 \\
\hline & \multirow{2}{*}{ Portugal } & Bond & 798 & 866.4617 & 437.1732 \\
\hline & & CDS & 798 & 658.414 & 333.0365 \\
\hline & \multirow{2}{*}{ Belgium } & Bond & 798 & 1.898 .066 & 106.3083 \\
\hline & & CDS & 798 & 1.427 .229 & 94.56208 \\
\hline
\end{tabular}




\begin{tabular}{cccccc}
\hline & Germany & Bond & 1138 & -15.73049 & 25.68482 \\
& & CDS & 1138 & 15.96701 & 4.267 .126 \\
& Italy & Bond & 1138 & 83.7797 & 44.89334 \\
& & CDS & 1138 & 135.3045 & 35.92924 \\
Fovereign sample & France & Bond & 1138 & 4.789279 & 24.98552 \\
(May 2014-Sep. 2018) & & CDS & 1138 & 33.23108 & 11.17922 \\
& Spain & Bond & 1138 & 56.0181 & 34.92935 \\
& & CDS & 1138 & 79.52461 & 18.49278 \\
& Portugal & Bond & 1138 & 1.419934 & 59.38633 \\
& & CDS & 1138 & 190.3584 & 71.00202 \\
& Belgium & Bond & 1138 & -1.431019 & 27.49624 \\
& & CDS & 1138 & 33.96508 & 12.07596 \\
\hline
\end{tabular}

cross check their outcome and have more reliable results. The presence of cointegration has been tested for each CDS premium and bond spread following these three steps:

The Dickey-Fuller test is performed for each time series in order to test if they are non-stationary.

Once the non-stationarity of the time series has been tested, a linear regression is performed, for testing the stationary of the residuals, by means of Dickey-Fuller test. If the residuals are stationary, then there is a linear combination which is stationary. This means that the two time series are cointegrated, as the Engle-Granger test requires.

Finally, the Johansen test is performed for estimating the rank of the cointegration matrix. If this is lower than the maximum rank, then the two time series are non-stationary and cointegrated.

As shown in Table 5, the pre-estimation tests confirm that almost all time series are non-stationary, apart from those of Deutsche Bank, for which the null hypothesis of stationary cannot be refused. The Dickey-Fuller test on the residuals of the linear regression between CDS premium and bond spread shows that the only residuals of the time series which resulted to be stationary are Santander, Thyssenkrupp and Air Liquid. For these entities, the null hypothesis of stationarity is accepted, so the relevant CDS premium and bond spread are cointegrated.

If the time series are cointegrated, the price discovery process is then analyzed by means of a VECM model (Vector Error Correction Model), that is a VAR model (Vector Autoregression) which includes the ECM (Error Correction Mechanism), which represents the deviation of long-run equilibrium confirmed by the cointegration test. The VECM model used in this work is:

$$
\begin{gathered}
\Delta C D S_{t}=\lambda_{1} Z_{t-1}+\sum_{i=1}^{p} \beta_{1 i} \Delta C D S_{t-i}+\sum_{i=1}^{p} \gamma_{1 i} \Delta \text { Bond }_{t-i}+\varepsilon_{1 t} \\
\Delta \text { Bond }_{t}=\lambda_{2} Z_{t-1}+\sum_{i=1}^{p} \beta_{2 i} \Delta C D S_{t-i}+\sum_{i=1}^{p} \gamma_{2 i} \Delta \text { Bond }_{t-i}+\varepsilon_{2 t}
\end{gathered}
$$


Table 5. Stationarity and cointegration tests.

\begin{tabular}{|c|c|c|c|c|c|}
\hline Sample & Entity & $\begin{array}{l}\text { CDS premium } \\
\text { Stationary }\end{array}$ & $\begin{array}{l}\text { Bond Spread } \\
\text { Stationary }\end{array}$ & $\begin{array}{l}\text { Residuals } \\
\text { Stationary }\end{array}$ & $\begin{array}{l}\text { Johansen } \\
\text { Test }\end{array}$ \\
\hline \multirow{7}{*}{ Financial corporate sample } & IntesaSanPaolo & NO & NO & NO & Non-Cointegrated \\
\hline & UniCredit & $\mathrm{NO}$ & NO & NO & Cointegrated \\
\hline & BNP Paribas & NO & NO & NO & Non-Cointegrated \\
\hline & SociétéGénérale & NO & NO & NO & Non-Cointegrated \\
\hline & DeutscheBank & YES & YES & - & - \\
\hline & CommerzBank & NO & NO & NO & Non-Cointegrated \\
\hline & Santander & NO & NO & YES & Non-Cointegrated \\
\hline \multirow{7}{*}{$\begin{array}{l}\text { Non-Financial corporate } \\
\text { sample }\end{array}$} & Vivendi & NO & NO & NO & Cointegrated \\
\hline & Thyssenkrupp & NO & NO & YES & Non-Cointegrated \\
\hline & Telecom Italia & NO & NO & NO & Cointegrated \\
\hline & Eni & NO & NO & NO & Non-Cointegrated \\
\hline & Air Liquid & NO & NO & YES & Non-Cointegrated \\
\hline & Orange & NO & NO & NO & Cointegrated \\
\hline & Telefonica & NO & NO & NO & Cointegrated \\
\hline \multirow{6}{*}{$\begin{array}{c}\text { Sovereign sample } \\
\text { (Apr. 2011-Apr. 2014) }\end{array}$} & Germany & NO & NO & NO & Cointegrated \\
\hline & Italy & NO & NO & NO & Non-Cointegrated \\
\hline & France & NO & NO & NO & Cointegrated \\
\hline & Spain & NO & NO & NO & Non-Cointegrated \\
\hline & Portugal & NO & NO & NO & Cointegrated \\
\hline & Belgium & NO & NO & NO & Cointegrated \\
\hline \multirow{6}{*}{$\begin{array}{l}\text { Sovereign sample } \\
\text { (May 2014-Sep. 2018) }\end{array}$} & Germany & NO & NO & NO & Non-Cointegrated \\
\hline & Italy & NO & NO & NO & Non-Cointegrated \\
\hline & France & NO & NO & NO & Cointegrated \\
\hline & Spain & NO & NO & NO & Cointegrated \\
\hline & Portugal & NO & NO & NO & Cointegrated \\
\hline & Belgium & NO & NO & NO & Non-Cointegrated \\
\hline
\end{tabular}

With:

$$
Z_{t-1}=C D S_{t-i}-\alpha-\beta_{0} \text { Bond }_{t-i}
$$

where:

$Z_{t-1}$ is the ECM, which represents the deviation of the CDS premiums and the bond spreads from their long-run equilibrium of null basis;

$\lambda_{1}$ and $\lambda_{2}$ are the adjustment parameters which correct the spreads' deviation toward the equilibrium, which accounts for the prices speed in correcting their mismatch in the long-run dynamic.

The significance and the sign of the adjustment parameters allow to analyze how fast they absorb the new information in the following way: 
If $\lambda_{1}$ is negative and significant, then the bond market absorbs information faster than the CDS one, so bond market leads the price discovery process.

If $\lambda_{2}$ is positive and significant, then the CDS market absorbs information faster than the bond one, so CDS market leads the price discovery process.

If both coefficients are significant with the correct sign, then both markets actively contribute to the price discovery process.

In the last case, the relevance of one of the two markets in the price discovery process is analyzed by means of the Gonzalo-Granger (GG) statistic, which measures the relative importance of both coefficients by means of the following ratios:

$$
\begin{aligned}
& G G_{1}=\lambda_{2} /\left(\lambda_{2}-\lambda_{1}\right) \\
& G G_{2}=\lambda_{1} /\left(\lambda_{2}-\lambda_{1}\right)
\end{aligned}
$$

As $G G_{1}+G G_{2}=1$, the $G G_{i}$ higher value defines the leader market. In particular, if $G G_{i}$ is next to 1, then the CDS market has a leader role, while if it is next to 0 , then the bond market has a leading role.

If the time series are not cointegrated, the price discovery process is analyzed by means of a VAR model as it follows:

$$
\begin{gathered}
\Delta C D S_{t}=\alpha_{1}+\sum_{i=1}^{p} \beta_{1 i} \Delta C D S_{t-i}+\sum_{i=1}^{p} \gamma_{1 i} \Delta \text { Bond }_{t-i}+\varepsilon_{1 t} \\
\Delta \text { Bond }_{t}=\alpha_{2}+\sum_{i=1}^{p} \beta_{2 i} \Delta C D S_{t-i}+\sum_{i=1}^{p} \gamma_{2 i} \Delta \text { Bond }_{t-i}+\varepsilon_{2 t}
\end{gathered}
$$

In this case, the leading market in the price discovery process will be determined by means of the Granger's causality test.

\section{Results}

As reported in Table 6, the price discovery process-analyzed by means of Granger causality test for all sub-periods-shows that the bond market has more often a leader role than the CDS market. Only for two entities of the sovereign sample, Belgium and Spain, the CDS market leads the price discovery process in the period May 2011-September 2018. For other entities, both CDS and bond market contribute in a similar way to the price discovery process of credit risk, is therefore not possible to identify a leader market in these cases.

Table 7 reports the results of the analysis of the price discovery process, by means of the sing and significance of adjustments coefficients of VECM model and also the Gonzalo-Granger statistic, for the entities characterized by stationary residuals, which shows that in all considered cases the bonds market has a leader role.

In summary, our results show that in the largest part of cases the bond market has a leader role in the price discovery process of the credit risk. Only in some cases, namely Spain and Belgium for the period May 2014-September 2018, is the CDS market to lead the process.

These results are in line with the more recent literature, which analyzes the price discovery process in the years following the 2008 financial crisis, while they 
Table 6. Granger-causality test after VAR model.

\begin{tabular}{|c|c|c|c|c|c|c|}
\hline \multirow[t]{2}{*}{ Sample } & \multirow[t]{2}{*}{ Entity } & \multicolumn{2}{|c|}{$\begin{array}{c}\text { Bond Spread do not } \\
\text { Granger-Cause CDS Spread }\end{array}$} & \multicolumn{2}{|c|}{$\begin{array}{c}\text { CDS Spread do not } \\
\text { Granger-Cause Bond Spread }\end{array}$} & \multirow{2}{*}{$\begin{array}{l}\text { Leader } \\
\text { Market }\end{array}$} \\
\hline & & Chi-Sq & Prob & Chi-Sq & Prob & \\
\hline \multirow{6}{*}{$\begin{array}{l}\text { Financial corporate } \\
\text { sample }\end{array}$} & IntesaSanPaolo & 78.12 & 0.000 & 2.4701 & 0.650 & BOND \\
\hline & UniCredit & 114.67 & 0.000 & 20.101 & 0.000 & Both \\
\hline & BNP Paribas & 88.489 & 0.000 & 5.3882 & 0.250 & BOND \\
\hline & SociétéGénérale & 97.651 & 0.000 & 2.0031 & 0.735 & BOND \\
\hline & DeutscheBank & 21.781 & 0.000 & 12.792 & 0.012 & Both \\
\hline & CommerzBank & 38.897 & 0.000 & 21.177 & 0.000 & Both \\
\hline \multirow{5}{*}{$\begin{array}{l}\text { Non-Financial } \\
\text { corporate sample }\end{array}$} & Vivendi & 90.265 & 0.000 & 6.557 & 0.195 & BOND \\
\hline & Telecom Italia & 86.053 & 0.000 & 25.934 & 0.000 & Both \\
\hline & Eni & 123.59 & 0.000 & 11.11 & 0.025 & Both \\
\hline & Orange & 74.034 & 0.000 & 8.9619 & 0.062 & BOND \\
\hline & Telefonica & 130.91 & 0.000 & 40.343 & 000 & Both \\
\hline \multirow{6}{*}{$\begin{array}{c}\text { Sovereign sample } \\
\text { (Apr. 2011-Apr. 2014) }\end{array}$} & Germany & 10.904 & 0.028 & 9.3121 & 0.054 & BOND \\
\hline & Italy & 4.9578 & 0.292 & 9.1929 & 0.056 & Unkown \\
\hline & France & 9.7788 & 0.044 & 7.1135 & 0.130 & BOND \\
\hline & Spain & 7.8046 & 0.099 & 1.5023 & 0.826 & Unkwon \\
\hline & Portugal & 18.859 & 0.001 & 34.116 & 0.000 & Both \\
\hline & Belgium & 14.445 & 0.006 & 10.618 & 0.031 & Both \\
\hline \multirow{6}{*}{$\begin{array}{l}\text { Sovereign sample } \\
\text { (May 2014-Sep. 2018) }\end{array}$} & Germany & 2.324 & 0.676 & 7.131 & 0.129 & Unkown \\
\hline & Italy & 35.56 & 0.000 & 33.482 & 0.000 & Both \\
\hline & France & 4.6841 & 0.321 & 7.3933 & 0.117 & Unkwon \\
\hline & Spain & 2.4732 & 0.649 & 16.464 & 0.002 & CDS \\
\hline & Portugal & 18.237 & 0.001 & 13.824 & 0.008 & Both \\
\hline & Belgium & 0.71121 & 0.950 & 12.177 & 0.016 & CDS \\
\hline
\end{tabular}

Table 7. GG Test after VECM model.

\begin{tabular}{|c|c|c|c|c|c|c|c|}
\hline \multirow{2}{*}{ Entity } & \multicolumn{2}{|c|}{$\lambda_{1}$} & \multicolumn{2}{|c|}{$\lambda_{2}$} & \multicolumn{2}{|c|}{$G G$} & \multirow{2}{*}{$\begin{array}{l}\text { Leader } \\
\text { Market }\end{array}$} \\
\hline & Coeff. & $\mathrm{P}>|\mathrm{z}|$ & Coeff. & $\mathrm{P}>|\mathrm{z}|$ & $G G_{1}$ & $G G_{2}$ & \\
\hline Intesa San Paolo & -4.65092 & 0.000 & 0.01766 & 0.768 & - & - & BOND \\
\hline Uni Credit & -0.40053 & 0.000 & -0.42987 & 0.000 & 14.65 & -13.65 & BOND \\
\hline BNP Paribas & -0.47468 & 0.000 & -2.70306 & 0.000 & 1 & 0 & BOND \\
\hline
\end{tabular}

are not in line with the literature prior to the 2008 financial crisis. The reasons for this difference are essentially due to two factors, one that characterizes the CDS contract of the government entities, and one common to all reference entities.

The first effect is related to the fact that the CDS contracts of the government entities are, in fact, denominated in USD, unlike those denominated in EUR, used by the previous literature. As confirmed by [8] the different currency de- 
nomination for CDS and bond determines an exchange rate risk that can cause an increase in the CDS-Bond basis due to a higher cost in CDS pricing. This is certainly valid for the corporate market, while it could be a weaker argument for the government bond market in a period of strong economic and political instability. Anyway, the new ISDA standards, introduced in 2011, require that the currency denomination of the CDS contract is no longer the EUR, but the USD. This motivation lies in the impact that a possible default of a Country may have on the stability of the entire European Economic Union, and therefore of the single currency, causing a depreciation of the EUR and consequently of the value of the protection purchased or sold.

The second effect is related to the development of the CDS market, the unsuitable use of these instruments during the 2008 financial crisis and the uncertainty of the contractual clauses, and the subsequent proposal from the ISDA to adopt the Big Bang Protocol in April 2009, in the aim of defining contractual standards and reducing systemic risk. The attention to these goals has been further strengthened by means of a reform of the financial regulation of the OTC derivatives market in America, with the Dodd-Frank Wall Street Reform and Consumer Protection Act (2010), and in Europe, with the European Market and Infrastructure Regulation (EMIR, 2012). Both made changes to the rules, controls and supervision in order to improve transparency. Finally, the two regulations made central clearing mandatory for many instruments, including CDS.

The combination of the two effects determined substantial changes in the price discovery processes, bringing bonds to take the lead in the largest number of cases.

\section{Conclusions and Remarks}

This study analyzed the possible links between CDS premiums and bond spreads, as regard both sovereign and corporate markets, in the period 2011-2018. Most of past studies analyzed this theme in the period 2011-2012. Since then, there have been many changes in the financial markets: the size and liquidity of the markets have changed, the performance of government bond yields in most European countries has been reversed and important regulatory changes regarding the negotiation of CDS have been introduced in European and US regulations. We thus verified if more up-to-date results confirm the empirical hypothesis proved by [1], about the theoretical equivalence between the CDS premium and the credit spread of the underlying bond, and on the price discovery process of the credit risk between the CDS market and the bond market.

The analysis of the CDS-Bond Basis for all the considered markets has shown that it is constantly away from parity and, in particular, positive on average. This is due to a decrease of both the CDS market liquidity and the bond credit spread liquidity, as confirmed by the cointegration analysis, reporting the absence of a null basis relationship for almost all the analyzed reference entities.

The analysis of the price discovery process of the credit risk between the CDS 
market and the bond market, examined by means of the VAR and VECM models, confirmed, in almost all the analyzed reference entities, the leader role that the bond spread market plays in the price discovery process of credit risk. This result is partially in line with the previous literature, whose aim was the study of the economic scenario prior and during the two financial crises of the first decade. The results are, in fact, in line with the literature that analyzed the price discovery process after the two financial crises. With the financial crisis of 2008 and the public debt crisis in 2011, in fact, the attention paid to the relationships between the CDS premium and the bond spread has increased, trying to identify which was the leader market in the credit risk pricing, as if this leading role was played by the CDS market, then a speculative use of these derivatives could create pressure on the bond market. These concerns have prompted the policy makers to improve the regulation of the credit derivatives market in order to place restrictions on the operation of CDS and to make the related trades more transparent and standardized, so reducing the systematic and counterparty risks of these instruments.

Our results show that the bond market has almost always a leader role in the price discovery process of the credit risk between the CDS market and the bond market, and just in some cases, all of which referring to sovereign bonds for the period May 2014-September 2018, is the CDS market to have a leader role.

These results bring important information for the arbitrage activity, which is always aimed at selecting the early signals of market variations, so to anticipate the market ongoing, and obtain some gain from it. The knowledge of which market has the leading role in influencing the subsequent markets performances is thus fundamental in this attitude.

\section{Acknowledgements}

This work was supported by Fondazione di Sardegna and Regione Autonomadella Sardegna.

\section{Conflicts of Interest}

The authors declare no conflicts of interest regarding the publication of this paper.

\section{References}

[1] Duffie, D. (1999) Credit Swap Valuation. Financial Analysts Journal, 55, 73-87. https://doi.org/10.2469/faj.v55.n1.2243

[2] Blanco, R., Brennan, S. and Marsh, I.W. (2005) An Empirical Analysis of the Dynamic Relationship between Investment-Grade Bonds and Credit Default Swaps. Journal of Finance, 60, 2255-2281. https://doi.org/10.1111/j.1540-6261.2005.00798.x

[3] Zhu, H. (2006) An Empirical Comparison of Credit Spreads between the Bond Market and the Credit Default Swap Market. Journal of Financial Services Research, 29, 211-235. https://doi.org/10.1007/s10693-006-7626-x

[4] Bai, J. and Collin-Dufresene, P. (2011) The Determinants of the CDS-Bond Basis 
during the Financial Crisis of 2006-2009. Discussion Papers. https://doi.org/10.2139/ssrn.2024531

[5] Fontana, A. (2010) The Persistent Negative CDS-Bond Basis During the 2007/08 Financial Crisis. Working Paper No. 2010-13, Department of Economics, University of Ca'Foscari, Venice. https://doi.org/10.2139/ssrn.1939184

[6] Coudert, V. and Gex, M. (2011) Credit Default Swap and Bond Markets: Which Leads the Other? CEPII, Working Paper No. 2011-02 February.

[7] Fontana, A. and Scheicher, M. (2010) An Analysis of Euro Area Sovereign CDS and Their Relation with Government Bonds. European Central Banks, Working Paper Series No. 1271, December 2010.

[8] O'Kane, D. (2012) The Link between Eurozone Sovereign Debt and CDS Pries. Bankers, Markets \& Investors, No. 177, March-April 2012.

[9] Palladini, G. and Portese, R. (2011) Sovereign Cds and Bond Pricing Dynamics in the Euro-Area. National Bureau of Economics Research, Working Paper 17586. https://doi.org/10.3386/w17586

[10] Amadei, L., Di Rocco, S., Gentile, M, Grasso, R. and Siciliano, G. (2011) I Credit Default Swap: Le caratteristiche e le interrelazioni con il mercato obbligazionario. Discussion Papers Consob.

[11] Patanè, M., Giorgione, A. and Vitagliano, M. (2016) A Model to Test the Price Discovery of Sovereign Credit Risk in the Eurozone. International Research Journal of Applied Finance, 7, 1-18.

[12] Johansen, S. (1988) Statistical Analysis of Cointegration Vectors. Journal of Economic Dynamics and Control, 12, 231-254. https://doi.org/10.1016/0165-1889(88)90041-3

[13] Engle, R.F. and Granger, C.W.J. (1987) Co-Integration and Error Correction: Representation, Estimation and Testing. Econometrica, 55, 251-276.

https://doi.org/10.2307/1913236 